\title{
COMPARATIVE STUDY OF ATORVASTATIN V/S ROSUVASTATIN IN HYPERLIPIDAEMIA
}

\author{
Krishan Kumar Oberoi' ${ }^{1}$, Hardip Singh ${ }^{2}$, Upasana Oberoi ${ }^{3}$, Priyanka ${ }^{4}$
}

${ }^{1}$ Associate Professor, Department of Medicine, Government Medical College, Amritsar.

${ }^{2}$ Assistant Professor, Department of Medicine, Government Medical College, Amritsar.

${ }_{3}^{3}$ Lecturer, Department of Obstetrics and Gynaecology, Government Medical College, Amritsar.

4 Junior Resident, Department of Medicine, Government Medical College, Amritsar.

ABSTRACT
BACKGROUND
Atherosclerosis of coronary arteries may manifest as myocardial infarction and angina pectoris and that of central nervous system
as non-haemorrhagic cerebrovascular accidents and transient ischaemic attacks.
The objective of this study is to compare the efficacy of atorvastatin and rosuvastatin on various aspects of lipid profile, viz.
serum total cholesterol, serum LDL-C, serum VLDL-C, serum HDL-C and serum triglycerides in Indian patients having dyslipidaemia
in this part of country.

\section{MATERIALS AND METHODS}

This was a randomised open study conducted on patients with abnormal lipid profile attending the OPD/ wards of Department of Medicine, Guru Nanak Dev Hospital, attached to Government Medical College, Amritsar in the year 2006. Based on our previous year OPD and indoor patients' records, the total number of patients with dyslipidaemia was 165 . Thinking that 100 patients would be achievable within 1 year, so a total of 100 patients were included in the study and the patients were divided randomly by lottery method into two groups of 50 patients each, Group A was put on Atorvastatin 20 mg daily and Group B was put on Rosuvastatin 20 mg daily. Out of total 100 patients, 50 (50\%) were males and $50(50 \%)$ were females. In Group A and B, there were 25 (50\%) males and $25(50 \%)$ females each. Lipid profiles were recorded in every patient at 0,6 weeks and then 12 weeks.

\section{RESULTS}

This was a randomised open study conducted on patients with abnormal lipid profile attending the OPD/ wards of Department of Medicine, Guru Nanak Dev Hospital, attached to Government Medical College, Amritsar in the year 2006. Based on our previous year OPD and indoor patients' records, the total number of patients with dyslipidaemia was 165 . Thinking that 100 patients would be achievable within 1 year so a total of 100 patients were included in the study and the patients were divided randomly by lottery method into two groups of 50 patients each; Group A was put on Atorvastatin 20 mg daily and Group B was put on Rosuvastatin 20 mg daily. Out of total 100 patients, 50 (50\%) were males and $50(50 \%)$ were females. In Group A and B, there were 25 (50\%) males and $25(50 \%)$ females each. Lipid profiles were recorded in every patient at 0,6 weeks and then 12 weeks.

\section{CONCLUSION}

Rosuvastatin lowers total serum cholesterol, serum LDL-C, serum TG and raises serum HDL-C more significantly as compared to Atorvastatin.

\section{KEYWORDS}

LDL, Atorvastatin, Rosuvastatin.

HOW TO CITE THIS ARTICLE: Oberoi KK, Singh H, Oberoi U, et al. Comparative study of atorvastatin v/s rosuvastatin in hyperlipidaemia. J. Evolution Med. Dent. Sci. 2017;6(88):6143-6146, DOI: 10.14260/jemds/2017/1334

\section{BACKGROUND}

Among conventional risk factors, dyslipidaemia is the most important modifiable risk in context of Indians. Derangement of any one or more than one of various lipid and lipoprotein constituents (e.g. total cholesterol, LDL-C, HDL-C, VLDL-C or $\mathrm{TG})$ have their relative contribution to atherogenesis. ${ }^{1}$

Atherosclerosis of coronary arteries may manifest as myocardial infarction and angina pectoris and that of central nervous system as non-haemorrhagic cerebrovascular accidents and transient ischaemic attacks. Peripheral dyslipidaemia mainly manifests two life-threatening abnormalities.

'Financial or Other Competing Interest': None.

Submission 06-09-2017, Peer Review 26-10-2017,

Acceptance 31-10-2017, Published 06-11-2017.

Corresponding Author:

Dr. Krishan Kumar Oberoi,

H. No. 13-C, Mata Kaulan Marg,

Kashmir Avenue, Amritsar.

E-mail: drkrishanoderoi@gmail.com

DOI: $10.14260 /$ jemds/2017/1334
Accelerated atherosclerosis and Acute pancreatitis. Other manifestations include xanthomas (tendon, palmar, eruptive, tubo-eruptive), Lipaemia retinalis and acute abdominal crisis. $^{2-3}$ Various drugs available to treat hyperlipidaemia include statins (HMG-CoA reductase inhibitors), nicotinic acid, fibric acid derivatives, bile acid sequestrants, cholesterol absorption inhibitors (ezetimibe) and fish oils (omega-3 fatty acids). HMG Co-A reductase inhibitors represent the major advances in prevention of coronary artery disease. In various primary and secondary prevention trial, treatment with these agents has been associated with $24 \%$ - 37\% decrease in coronary mortality and morbidity. ${ }^{4}$ They are the most widely used hypolipidaemic drugs worldwide.

\section{MATERIALS AND METHODS}

In this open randomised comparative study, 100 patients with abnormal lipid profile attending the outpatient department as well as admitted in Guru Nanak Dev Hospital attached to Government Medical College, Amritsar, were taken in the year 2006. 


\section{Sample Size}

The design selected was randomised, double-blinded study. A total of 100 patients were included in the study. The samples of the study were selected by randomisation procedure without replacement. Lottery was done to randomly select the subjects in Group A (50) and Group B (50). The name of patients who fulfilled the inclusion criteria and who were available were written on a slip of paper and put in a bowl and mixed thoroughly. The investigator picked up slips blindfolded and they were the subjects for study. The first pick was taken for Group A and the second one was considered for Group B. Each time before drawing a slip, slips were mixed thoroughly in the bowl. Group A was put on atorvastatin 20 mg daily and Group B on Rosuvastatin 20 mg daily. Out of total 100 patients $50(50 \%)$ were males, 50 (50\%) were females. In Group A and B, there were 25 (50\%) males and 25 $(50 \%)$ females each. Lipid profile was recorded at 0,6 and 12 weeks.

\section{Inclusion Criteria}

Patients selected for the present study had-

1. S. cholesterol $>200 \mathrm{mg} \%$.

2. S. LDL-C $>100 \mathrm{mg} \%$.

3. $\mathrm{S}$. TG $>200 \mathrm{mg} \%$.

\section{Exclusion Criteria}

1. Hypersensitivity to statins.

2. Patients with diabetes mellitus.

3. Pregnant/ nursing mothers.

4. Active liver disease/ Renal insufficiency/ Nephrotic syndrome.

5. Uncontrolled hypothyroidism.

6. Chronic alcoholics.

7. Acute myocardial infarction within preceding 3 months.

8. Known gastric acid disease/ peptic ulcer disease.

9. Pancreatitis/ cholelithiasis without cholecystectomy.

10. Concurrent intake of drugs affecting plasma lipid concentration or known to interact with statins.

\section{Clinical Examination and Investigations}

Detailed history and thorough general physical examination was done. Investigations were-

\section{Followup}

The Lipid profile was done on followup at 6 weeks and 12 weeks.

\section{Statistical Tools}

The information collected regarding all the selected cases was recorded in a Master chart. Data analysis was done with the help of computer using software SPSS (Version 15). Results were tabulated in the form of mean \pm S.D. and analysed using student's ' $t$ ' test and the level of significance was determined as its ' $p$ ' value with $p<0.05$, taken as statistically significant.

\section{RESULTS}

Our study was conducted on 100 patients with abnormal lipid profile, of which males and females were almost equal in number ( 50 males and 50 females) and there was no sex bias.
In Group $A$ the mean age among males was $56.5 \pm 9.73$ years, in females it was $55.25 \pm 9.35$ years. In Group B the mean age among males was $53.80 \pm 6.56$ years and in females it was $54.41 \pm 4.49$ years. Distribution of other risk factors for coronary artery disease was also similar in Group A/B (Hypertension 27/33, Smoking 11/7 and Family History of CAD 12/10). In both Groups A and B, at the end of 6 and 12 weeks the decrease was highly significant ( $p$ value $<0.001$ ). Maximum fall occurred in first 6 weeks in both groups. In Group B, the percentage reduction was more than Group A and was highly significant ( $p$ value $<0.001$ ).

\begin{tabular}{|c|c|c|c|}
\hline Comparison & $\begin{array}{c}\text { 0 vs 6 } \\
\text { Weeks }\end{array}$ & $\begin{array}{c}\text { 6 vs 12 } \\
\text { Weeks }\end{array}$ & $\begin{array}{c}\text { 0 vs 12 } \\
\text { Weeks }\end{array}$ \\
\hline Group A & $27.44 \%$ & $9.036 \%$ & $33.99 \%$ \\
\hline Group B & $33 \%$ & $10.77 \%$ & $40.21 \%$ \\
\hline \multicolumn{3}{|c|}{ Table 1. Mean Percentage Decrease in Serum Total } \\
Cholesterol at 6 and 12 Weeks \\
\hline
\end{tabular}

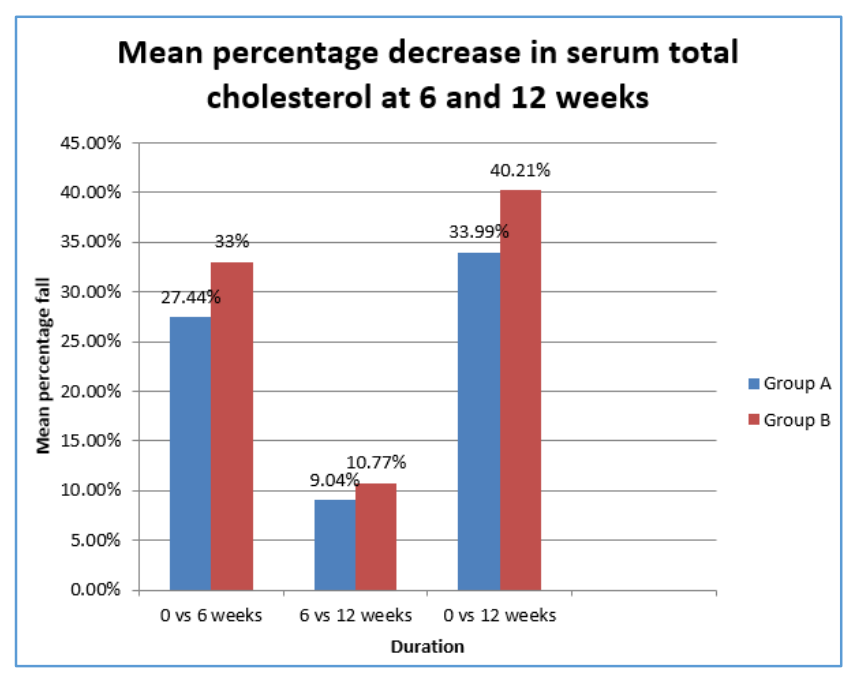

In both Groups $A$ and $B$, at the end of 6 and 12 weeks the decrease was highly significant $(\mathrm{p}<0.001)$. Maximum fall occurred in first 6 weeks in both groups. In Group B, the percentage reduction was more than Group A and was highly significant $(\mathrm{p}<0.001)$.

\begin{tabular}{|c|c|c|c|}
\hline Comparison & $\begin{array}{c}\text { 0 vs 6 } \\
\text { Weeks }\end{array}$ & $\begin{array}{c}\text { 6 vs 12 } \\
\text { Weeks }\end{array}$ & $\begin{array}{r}\text { 0 vs 12 } \\
\text { Weeks }\end{array}$ \\
\hline Group A & $38.89 \%$ & $14.62 \%$ & $47.82 \%$ \\
\hline Group B & $45.78 \%$ & $18.10 \%$ & $55.56 \%$ \\
\hline \multicolumn{3}{|c|}{ Table 2. Mean Percentage Decrease in Serum LDL- } \\
C Levels at 6 and 12 Weeks \\
\hline
\end{tabular}

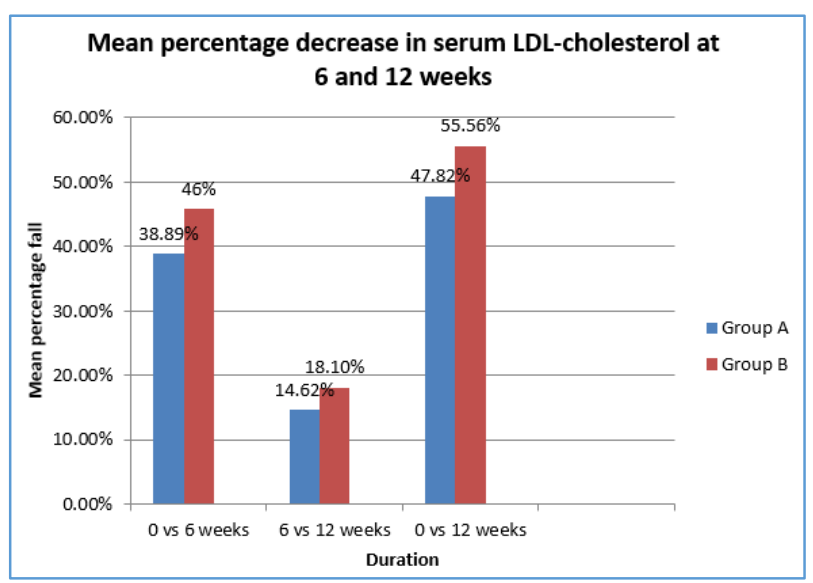




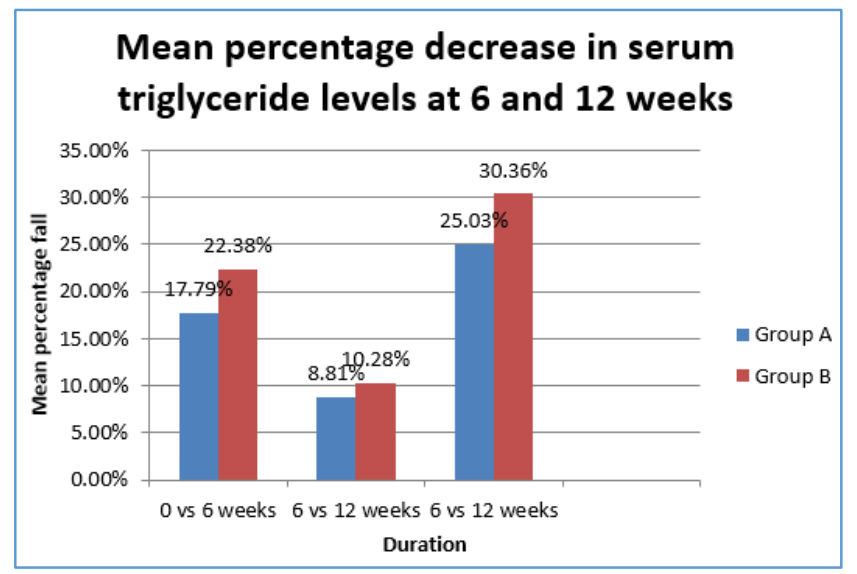

In both Groups $A$ and $B$, at the end of 6 and 12 weeks the decrease was highly significant $(p<0.001)$. Maximum fall occurred in first 6 weeks in both groups. In Group B, the percentage reduction was more than Group A and was highly significant $(\mathrm{p}<0.001)$.

\begin{tabular}{|c|c|c|c|}
\hline Comparison & $\begin{array}{c}\text { 0 vs 6 } \\
\text { Weeks }\end{array}$ & $\begin{array}{c}\text { 6 vs 12 } \\
\text { Weeks }\end{array}$ & $\begin{array}{c}\text { 0 vs 12 } \\
\text { Weeks }\end{array}$ \\
\hline Group A & $17.79 \%$ & $8.81 \%$ & $25.03 \%$ \\
\hline Group B & $22.38 \%$ & $10.28 \%$ & $30.36 \%$ \\
\hline Table 3. Mean Percentage Decrease in Serum Triglyceride \\
Levels at 6 and 12 Weeks \\
\hline
\end{tabular}

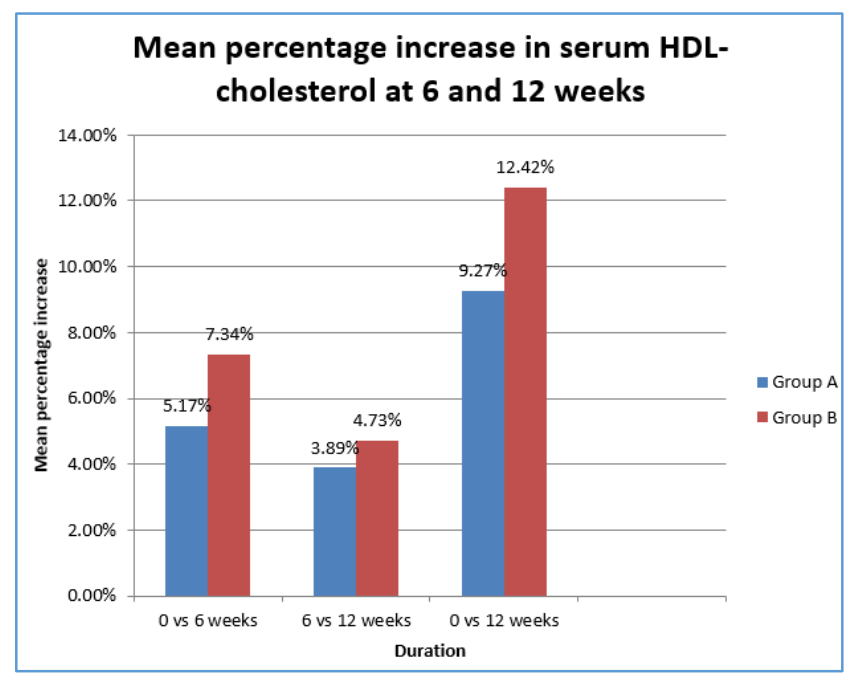

In Group A, the decrease in serum triglyceride at the end of 6 weeks was very significant $(p<0.01)$ and at the end of 12 weeks it was highly significant ( $p<0.001)$. In Group B, the change at end of 6 and 12 weeks was highly significant $(p<0.001)$. The maximum fall occurred in first 6 weeks in both the groups.

\begin{tabular}{|c|c|c|c|}
\hline Comparison & $\begin{array}{c}\text { 0 vs 6 } \\
\text { Weeks }\end{array}$ & $\begin{array}{c}\text { 6 vs 12 } \\
\text { Weeks }\end{array}$ & $\begin{array}{c}\text { 0 vs 12 } \\
\text { Weeks }\end{array}$ \\
\hline Group A & $5.17 \%$ & $3.89 \%$ & $9.27 \%$ \\
\hline Group B & $7.34 \%$ & $4.73 \%$ & $12.42 \%$ \\
\hline \multicolumn{4}{|c|}{ Table 4. Mean Percentage Increase in Serum HDL-C at 6} \\
and 12 Weeks
\end{tabular}

In Group A the increase at the end of 6 weeks was not significant $(p>0.05)$, but very significant $(p<0.01)$ at the end of 12 weeks. In Group B, the percentage increase at the end of 6 and 12 weeks was highly significant $(\mathrm{p}<0.001)$.

\section{DISCUSSION}

In the present study, there was statistically highly significant $(\mathrm{p}<0.001)$ fall in serum total cholesterol and serum LDL-C levels from baseline in both the groups.

The mean percentage fall at 12 weeks with atorvastatin $10 \mathrm{mg}$ as reported by Olsson et $\mathrm{al}^{5}$ is $28 \%, 39 \%$ and $16 \%$ respectively. The mean percentage fall at 12 weeks with Atorvastatin $10 \mathrm{mg}$ was reported to be $26.8 \%, 35.0 \%$ and $17.8 \%$ respectively by Schwartz et al. ${ }^{6}$ The percentage fall in serum triglyceride levels in Group A at the end of 6 weeks was less, but very significant ( $p<0.01$ ), but it was highly significant $(p<0.001)$ at the end of 12 weeks; whereas in case of Group $B$ the percentage fall in serum triglyceride levels was highly significant $(p<0.001)$ both at the end of 6 and 12 weeks.

The difference in mean percentage fall in the levels of total serum cholesterol, serum triglycerides and serum LDL-C (Group A vs Group B) was highly significant $(\mathrm{p}<0.001)$ and in favour of Group B (Rosuvastatin group).

Both Atorvastatin and Rosuvastatin brought a rise in serum HDL-C levels. In Group A, the rise was less but very significant $(p<0.01)$ at the end of 6 weeks. But it was highly significant $(p<0.001)$ at the end of 12 weeks. In Group B, the rise was highly significant ( $p<0.001)$, both at the end of 6 and 12 weeks.

The difference in mean percentage rise in the levels of serum HDL-C (Group A vs Group B) was statistically significant $(p<0.005)$ and was in favour of Group B.

The present study has shown that both Atorvastatin and Rosuvastatin have their effects on all lipid parameters. Both reduce total serum cholesterol, serum LDL-C levels, serum triglycerides and raised serum HDL-C levels with Rosuvastatin having more potent effect on all parameters.

In the present study, in Group A 39 (78\%) patients achieved the serum LDL-C ATP III goal and in Group B 45 (90\%) patients achieved the serum LDL-C ATP III goal at the end of 12 weeks. This difference is statistically significant $(\mathrm{p}<$ 0.05 ) and in favour of Group B. The percentage of patient achieving the serum LDL-C goals was almost similar in present study to that reported by various landmark studies.

Both the drugs in present study were well tolerated. No patient had any serious side effects and no patient withdrew from the study. GI tract disturbances were main side effects occurring in $10 \%$ patients in Group A and $8 \%$ patients in Group B. In the present study, Myalgia occurred in $2 \%$ patients of Group A and 4\% patients of Group B. No patient in the present study had raise in serum ALT levels. Comparing the overall incidence of side effects between Group $A$ and Group B, there was no significant difference between the two groups $(p>0.05)$.

\section{CONCLUSION}

1. Both Atorvastatin $20 \mathrm{mg} /$ day and Rosuvastatin 20 $\mathrm{mg} /$ day led to high significant $(<0.001)$ fall in levels of serum total cholesterol, serum LDL-C and serum triglycerides, Rosuvastatin having more potent effect on these parameters.

2. Rise in serum HDL-C levels with Rosuvastatin was highly significant $(p<0.001)$. Atorvastatin also raises serum 
HDL-C levels, but less as compared to rosuvastatin $(\mathrm{p}<0.01)$.

3. The primary goal of serum LDL-C was achieved by $78 \%$ of Group A and 90\% of Group B and the difference was statistically significant $(\mathrm{p}<0.05)$.

4. There was statistically no significant difference ( $p>0.05)$ in gastrointestinal and other side effects of Group A and $\mathrm{B}$.

To conclude, the results of this study suggest that when both Atorvastatin and Rosuvastatin are used in the same dose and for same duration in comparable to dyslipidaemic groups Rosuvastatin lowers Total Serum Cholesterol, Serum LDL-C, Serum Triglycerides and raises Serum HDL-C more significantly as compared to Atorvastatin. Further larger studies in this regard are required.

\section{REFERENCES}

[1] Pedersen TR, Kjekshus J, Berg K, et al. Randomised trial of cholesterol lowering in 4444 patients with coronary heart disease: the scandinavian simvastatin survival study (4S). 1994. Atheroscler Suppl 2004;5(3):81-7.
[2] Grundy SM, Balady GJ, Criqui MH, et al. Primary prevention of coronary heart disease: guidance from Framingham: a statement for healthcare professionals from the AHA task force on risk reduction. American heart association. Circulation 1998;97(18):1876-87

[3] Jeppensen J, Hein HO, Suadicani P, et al. Triglyceride concentration and ischaemic heart disease: an eight year follow up in Copenhagen male study. Circulation 1998;97(11):1029-36.

[4] Gotto AM. Safety and statin therapy: reconsidering the risks and benefits. Arch Intern Med 2003;163(6):6579.

[5] Olsson AG, Istad $\mathrm{H}$, Luurilla 0 , et al. Effects of rosuvastatin and atorvastatin compared over 52 weeks of treatment in patients with hypercholesterolemia. Am Heart J 2002;144(6):104451.

[6] Schwartz GG, Bolognese MA, Tremblay BP, et al. Efficacy and safety of rosuvastatin and atorvastatin in patients with hypercholesterolemia and a high risk of coronary heart disease: a randomized controlled trial. Am Heart J 2004;148(1):e4. 